\title{
Combined Central Retinal Artery and Vein Occlusion with Ischemic Optic Neuropathy After COVID-19 Vaccination
}

\author{
Sol Lee' \\ Kamalesh K Sankhala ${ }^{2}$ \\ Swaraj Bose ${ }^{3}$ \\ Ron P Gallemore (D) \\ 'Department of Clinical Research, Retina \\ Macula Institute, Torrance, CA, USA; \\ ${ }^{2}$ Cedars-Sinai Medical Center, Beverly \\ Hills, CA, USA; ${ }^{3}$ NeuroOphthalmology \& \\ Orbital Surgery, Cedars-Sinai Medical \\ Towers, NeuroEyeOrbit Institute, Los \\ Angeles, CA, USA
}

Purpose: To report a case of combined central retinal vein and artery occlusion that evolved into ischemic optic neuropathy following the Pfizer COVID-19 vaccination.

Methods: Patient was followed with optical coherence tomography (OCT), fluorescein angiography, and Humphrey visual field.

Results: Patient was able to recover vision from count fingers to 20/30 on a combination of aflibercept, steroidal and non-steroidal anti-inflammatories, a diuretic (acetazolamide), antiplatelet agents (aspirin and pentoxifylline), and an anticoagulant (apixaban).

Conclusion: COVID-19 vaccination may be associated with a myriad of sight-threatening ocular thrombotic conditions, which may respond to a combination of anti-inflammatory and anticoagulant therapies.

Keywords: COVID-19 vaccine, Pfizer, vascular thrombosis, NAION

\section{Introduction}

The COVID vaccines are now available, of which there are multiple, for prophylaxis against the COVID-19 related infection responsible for the worldwide pandemic. ${ }^{1}$ Efforts were made to minimize complications associated with the vaccine, including preservative-free formulations. ${ }^{2}$ Numerous clinical trials demonstrated safety and efficacy with a low complication rate. ${ }^{3,4}$ Select patients, however, have experienced complications, and vascular thrombosis has been one of them. ${ }^{5-7}$ Here, we report a complex case of ocular thrombosis causing severe vision loss in a patient following COVID vaccination with the Pfizer vaccine, management strategies, and rationale.

\section{Case Report}

A 34-year-old Caucasian male underwent vaccination with the Pfizer vaccine, one of two mRNA vaccines currently available in the United States, ${ }^{1}$ receiving the first dose on March 1, 2021, and the second dose on March 22, 2021. Approximately 10 to 12 days after the second injection, he noticed blurred vision in his left eye. He was seen by a retina specialist who diagnosed an early vein occlusion and prescribed baby aspirin and observation. The following day, he noticed his vision deteriorating further, at which time he became count fingers and saw a specialist at another institution who felt a combined central retinal artery occlusion (CRAO) and central vein occlusion (CRVO) was the diagnosis for which the patient was advised

Correspondence: Ron P Gallemore Department of Clinical Research, Retina Macula Institute, 420I Torrance Blvd, Suite 220, Torrance, CA, 90503, USA Tel + | 310-413-7020

Email rongallemoremd@gmail.com 
that there was no proven treatment. Hyperbaric oxygen was offered as an experimental intervention, which he received one treatment of, but the following day he felt he was worse. Indeed, there were increasing retinal hemorrhages, particularly around the disc, and his vision remained count fingers. At that time, we saw the patient and diagnosed a CRVO based on the fundus appearance of dilated and tortuous retinal veins, a few scattered blot hemorrhages in all 4 quadrants, disc edema, and exudative macular detachment on the macular OCT (Figure 1). A history of retinal whitening with a cherry red spot was reportedly noted the day before at the other institution and given the minimal intraretinal edema, a diagnosis of combined CRAO-CRVO was also made. Fluorescein angiography (FA) demonstrated delayed central retinal vein filling, and the retina was mildly thickened on OCT, but frank cystoid macular edema was not present (Figures 1 and 2). There is also delayed arterial filling, particularly in the more distant branches even after 50 seconds, which is consistent with partial obstruction of the central retinal artery (Figure 2). The few blot hemorrhages are highlighted by the FA. Baseline average RNFL thickness was 93um OD and 153 um OS. Given the new exudative detachment, venous stasis, and a diagnosis of CRVO, it was felt that aflibercept might give the best chance of restoration of vision. He received an intravitreal injection of aflibercept, ${ }^{8-11}$ as well as an anti-inflammatory cocktail of dexamethasone, bromfenac, and acetazolamide to treat the edema. $^{12}$ A time course of macular OCT changes, RNFL studies, and interventions is shown in Figure 3.
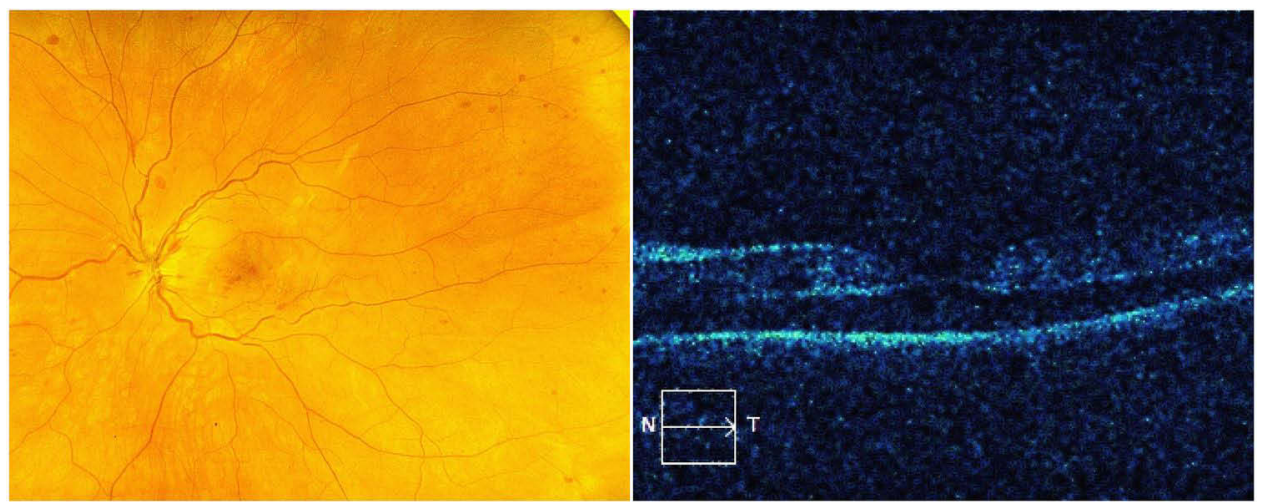

Figure I (Left) Fundus photo showing scattered dot blot hemorrhages. (Right) OCT contour map showing serous detachment but no overt cystic edema.



Figure 2 FA studies demonstrate delayed central retinal vein filling in the left eye. While the central retinal arteries began filling 6 seconds after the fluorescein dye injection was complete (approximately 16 seconds after the injection was initiated), complete filling of the peripheral branches of the central retinal artery progressed but was never complete even by the end of the angiogram ( 4 minutes and 30 seconds - not shown). 
Patient underwent work-up the night before at the emergency room and his complete blood count (CBC), comprehensive metabolic panel (CMP), troponin, and prothrombin time test with international normalized ratio (PT/ INR) were all unremarkable. His cholesterol panel was notable for elevated total cholesterol (227) and LDL (159). Hemoglobin A1c was normal at 5.4. His erythrocyte sedimentation rate (ESR) was mildly elevated at 26 , but C-reactive protein (CRP) was normal. EKG showed no ischemic changes or evidence of cardiac arrhythmia. Computed tomography (CT) of the brain and CT angiography of the head and neck were negative for acute pathology. X-ray of the chest showed no acute cardiopulmonary process. Echocardiogram was normal and carotid ultrasound was unremarkable. Patient was also tested for Factor V Leiden, Protein S and Protein C levels, activated protein $\mathrm{C}$ resistance, antiphospholipid and anticardiolipin antibodies, lupus anticoagulant, antithrombin III, Factor VIII, Factor XI, D-Dimer, serum electrophoresis, cryoglobulin levels, lymphoma, antinuclear antibody test, angiotensin converting enzyme (ACE), lysozyme, rapid plasma reagin (RPR), fluorescent treponemal antibody test absorption test (FTA-ABS), which were all unremarkable. He was found to be hypertensive upon evaluation in the emergency room with a blood pressure (BP) of 160/77, but measurements in our office (117/70) and in another office (126/79) did not support the diagnosis of hypertension.

Given the mildly elevated ESR, suspected inflammatory immune response, and data that systemic steroids can suppress the systemic inflammatory response associated with COVID-19 infection, ${ }^{13}$ the patient was prescribed oral methylprednisolone $4 \mathrm{mg}$. The following day, he continued to deteriorate with increasing disc edema (23um increase in RNFL thickness to 176um), increasing macular edema (37um increase in CMT to 358um), and further darkening of his vision. A hematology consult had been obtained and anticoagulation was recommended with low molecular weight heparin (LMWH), which might provide the benefit of rapid onset that was also reversible. ${ }^{14} \mathrm{He}$ self-administered $80 \mathrm{mg} / 0.8 \mathrm{~mL}$ of LMWH on April 9, 2021. The next day, he felt he was the same or worse, and an OCT difference map of the macula showed some areas of improvement, though the FA was about the same with comparable blot hemorrhages and delayed filling time of the central retinal vein (not shown). A literature review of COVID vaccine-related complications raised the possibility that heparin or heparin-like binding proteins could increase coagulation ${ }^{15}$ so we elected to switch to apixaban. Patient was checked for heparin-induced thrombocytopenia (HIT) and found to be negative. The following day, however, he deteriorated further with increasing disc edema (RNFL of 214um OS) and some evidence of retinal whitening, suggesting a worsening of the arteriolar component of the vascular thrombosis. Given the disc edema which has the appearance of nonarteritic ischemic optic neuropathy (NAION), data which suggests high dose systemic steroids might be useful, ${ }^{13}$ the history of elevated ESR, and the inflammatory immune response to COVID infection and presumably the vaccine as well, high dose IV methylprednisolone was recommended: 1 gram per day for three days. ${ }^{13}$ The day after the first dose of IV methylprednisolone, there was clearly some improvement in some areas, and the patient also noted improvement with recovery of vision to 20/400. After a 3-day course of IV methylprednisolone and 4 days of apixaban, the patient's BCVA improved to $20 / 80$, and we started him on an oral prednisone taper beginning at $80 \mathrm{mg}$ QD. Patient still had persistent disc edema, and since the patient's subjective visual improvement was minimal despite the eye chart data suggesting otherwise, we added pentoxifylline 400mg BID PO as there have been reports that this drug may ameliorate thrombosis and be effective against NAION. ${ }^{16}$ Patient continued this course, and his BCVA improved to a peak of $20 / 30$ after 3 weeks from initial presentation. While the patient recovered 20/30 vision, he continued to note light and color desaturation and exhibited a $2+$ relative afferent pupillary defect in the left eye. The most recent RNFL study demonstrated nerve fiber layer loss in the superior pole of the nerve consistent with the diagnosis of NAION. There was also a residual inferior altitudinal visual field defect (Figure 4).

\section{Discussion}

Retinal vascular occlusions encompass one of the most common reasons for vision loss, particularly in older populations with risk factors such as hypertension, dyslipidemia, diabetes mellitus, glaucoma, vasculitis, or a hypercoagulable state. It includes disorders such as retinal vein occlusions (RVO), retinal artery occlusions (RAO), and even ischemic optic neuropathy (ION), all of which present in a similar fashion but have different pathogenesis and clinical findings. An RVO is generally characterized by the presence of retinal hemorrhages, macular edema, cotton wool spots, dilated/tortuous veins, and disc edema, while an RAO often presents with 


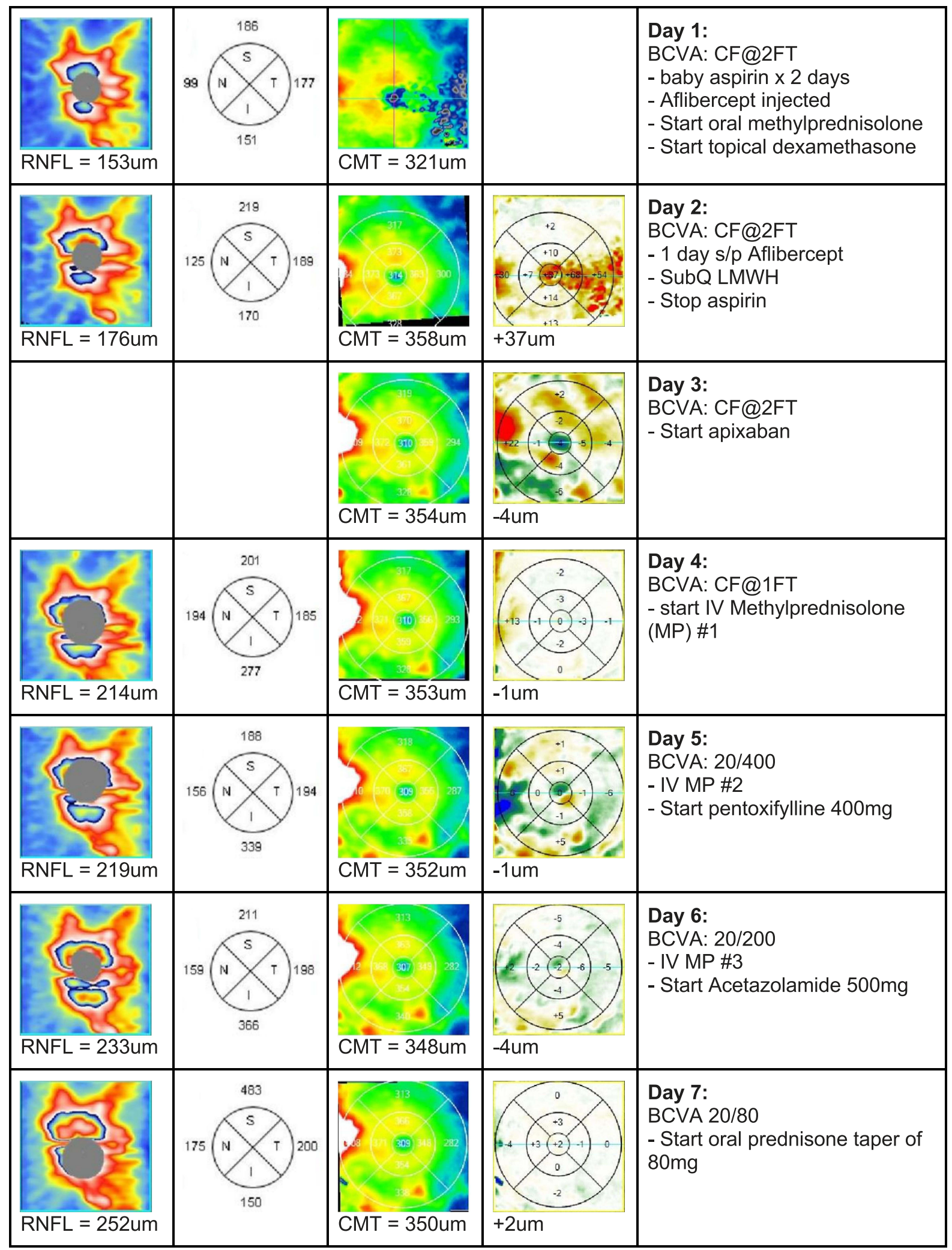

Figure 3 Continue. 


\begin{tabular}{|c|c|c|c|c|}
\hline $\begin{array}{c}\text { RNFL }=190 \mathrm{~mm} \\
\text { RN }\end{array}$ & $\underbrace{214}_{228}$ & CMT = 338um & $-12 \mathrm{um}$ & $\begin{array}{l}\text { Day 14: } \\
\text { BCVA: } 20 / 50\end{array}$ \\
\hline RNFL $=186 \mathrm{um}$ & $150 \underbrace{215}_{211}$ & $\begin{array}{l}(293) \\
\text { CMT }=332 \mathrm{um}\end{array}$ & $x_{-6 u m}^{x}$ & $\begin{array}{l}\text { Day 16: } \\
\text { BCVA: } 20 / 50\end{array}$ \\
\hline RNFL = 167um & 203 & $\begin{array}{l}\text { CMT }=312 \mathrm{um} \\
(2618)\end{array}$ & $\underbrace{x_{-1}^{-1}}_{-20 u m}$ & $\begin{array}{l}\text { Day 21: } \\
\text { BCVA: 2/30 }\end{array}$ \\
\hline RNFL = 139um & 104 & CMT = 299um & $-13 u m$ & $\begin{array}{l}\text { Day 28: } \\
\text { BCVA: } 20 / 40\end{array}$ \\
\hline RNFL = 95um & $\frac{1}{127}$ & $\mathrm{CMT}=280 \mathrm{um}$ & $-19 u m$ & $\begin{array}{l}\text { Day 50: } \\
\text { BCVA: } 20 / 30\end{array}$ \\
\hline
\end{tabular}

Figure 3 Optical coherence tomography studies of the optic nerve and macula during course of treatment. Columns left to right: Contour map of the optic nerve with average RNFL thickness noted below, 4 quadrant map of RNFL measurements, contour map of central macula with average central macular thickness noted below (defined as the average of five central quadrants), difference map of macular thickness showing change in retinal thickness in each sector (the green to blue color indicates progressive larger decrease in thickness, whereas the yellow to red color changes indicated progressively larger increase in thickness). The final right-hand column represents the day of treatment following initial visit and the specific treatments administered.

ischemic retinal whitening and/or a cherry-red fovea. Unlike an RVO or an RAO, an ION event results from a lack of blood flow to the optic nerve and is non-embolic in nature but may present with the same unilateral loss of vision. It is often associated with disc edema and a small cup-to-disc ratio in the contralateral eye. Here, we report a case of combined central retinal vein and artery occlusion that evolved into ischemic optic neuropathy in a young patient following COVID-19 vaccination.
There is now a growing literature reporting systemic thrombotic complications associated with COVID vaccination and the COVID disease itself. The complications are probably caused by similar mechanisms in most cases, specifically inflammation-induced thrombosis. The AstraZeneca vaccine, currently available in Europe, has had perhaps the greatest numbers of complications, and a European task force was in place advising on treatment strategies for such complications. ${ }^{15}$ Specifically, the 

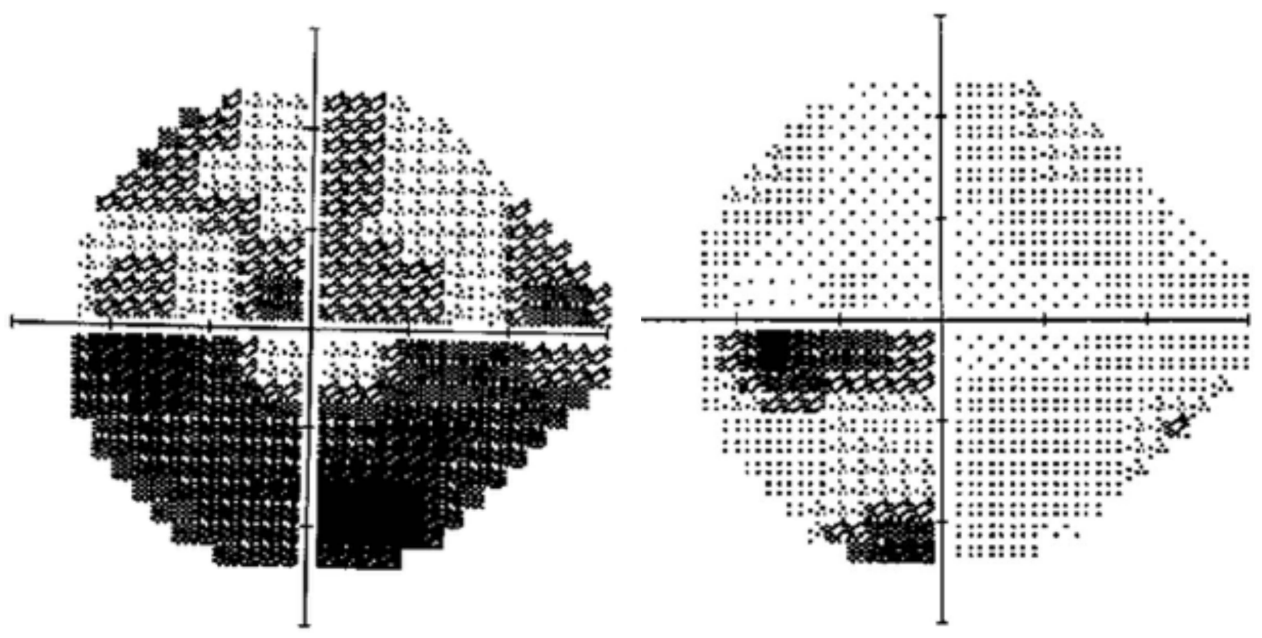

Figure 4 Visual field of the left eye at day 5 and day 60 .

Society of Thrombosis and Haemostasis Research (GTH) provided guidelines on the recognition, diagnosis, and treatment of thrombosis associated with the AstraZeneca vaccine. It shares pathophysiological features with heparin-induced thrombocytopenia (HIT) and is referred to as vaccine-induced prothrombotic immune thrombocytopenia (VIPIT). The paper advised the use of direct oral anticoagulants (DOACs). We initially selected low molecular weight heparin because of its ease of outpatient administration, but upon learning of the possibility of HIT and the fact that heparin may make COVID-vaccine related thrombosis worse by inducing platelet-activating antibodies and causing massive platelet activation, ${ }^{15}$ we subsequently chose apixaban because of its ease of administration, mechanism of action, and relative rapid onset. ${ }^{17}$ Following apixaban, there was some subjective improvement in vision, but the optic nerve remained edematous.

The use of systemic corticosteroids was prompted by the finding that in COVID itself, the systemic inflammation was associated with thrombosis, and adding systemic steroids reduced all complications. ${ }^{13}$ The patient was initially treated with topical dexamethasone and oral methylprednisolone, but after the development of increasing disc edema and a picture of NAION, we initiated a course of higher dose systemic steroids, namely $1 \mathrm{~g}$ of IV methylprednisolone for three days, followed by an oral steroid taper. Although CRVO alone is associated with disc edema, the rotation of the edema around the nerve and the progressive edema without progression of the macular edema or blot hemorrhages associated with the CRVO suggest the diagnosis of NAION. Atrophy of the superior pole of the optic nerve after the resolution of disc edema also supports this diagnosis. There is data to suggest systemic steroids may also help NAION, ${ }^{18}$ although the data is limited, and a number of authors indicate there is no proven therapy. ${ }^{19-20}$ In addition to methylprednisolone, we added pentoxifylline, which has also been shown to be of questionable benefit in NAION. ${ }^{16,21}$ It is unclear exactly if there was benefit from this as it was given a day after the course of IV methylprednisolone was started, but there was continued dramatic improvement observed during that time. We threw everything in the kitchen sink at the problem because the patient's visual function was not dramatically improving, and there was evidence of progressive retinal and optic nerve ischemia. There was an argument for each step that we took, but further studies will be required to support an association between our interventions and the recovery observed. In the end, there was restoration of both venous and arterial circulation and recovery of functional vision for the patient.

While we cannot establish a definitive cause and effect between the COVID vaccine and this complex case, this may provide some treatment guidelines for approaching other similar complications. We have no evidence for prior COVID exposure of the patient, but it is also conceivable that he had an asymptomatic infection and subsequent challenge with the vaccine precipitated a hyperimmune response and/or hypercoagulable state. His high cholesterol level and possible labile hypertension may have been comorbidities in increasing his risk for a vascular event with vaccination in this case. Regardless, this is a rare complication, and we believe the benefits of the vaccine 
for the individual and the population far outweigh the potential risks.

\section{Patient Consent}

We confirm that any aspect of the work covered in this manuscript that has involved human patients has been conducted with the ethical approval of all relevant bodies. Informed written consent has been obtained from all patients to have case details and any accompanying images published.

\section{Acknowledgments}

No institutional approval was required for the publishing of this case report.

\section{Author Contributions}

All authors made a significant contribution to the work reported, whether that is in the conception, study design, execution, acquisition of data, analysis and interpretation, or in all these areas; took part in drafting, revising or critically reviewing the article; gave final approval of the version to be published; have agreed on the journal to which the article has been submitted; and agree to be accountable for all aspects of the work.

\section{Funding}

No grant support or funding was given.

\section{Disclosure}

These authors report no conflicts of interest in this work.

\section{References}

1. Center for Disease Control and Prevention. Different COVID-19 vaccines. Available from: https://www.cdc.gov/coronavirus/2019ncov/vaccines/different-vaccines.html. Accessed May 24, 2021.

2. ASHP, ISMP, USP. FAQ for optimizing COVID-19 vaccine preparation and safety. Available from: https://www.ashp.org/-/media/assets/ pharmacy-practice/resource-centers/Coronavirus/docs/FAQ-optimizing -covid-vaccine-prep-safety.ashx. Accessed May 24, 2021.

3. Polack FP, Thomas SJ, Kitchin N, et al. Safety and efficacy of the BNT162b2 mRNA Covid-19 vaccine. N Engl J Med. 2020;383 (27):2603-2615. doi:10.1056/NEJMoa2034577

4. Baden LR, El Sahly HM, Essink B, et al. Efficacy and safety of the mRNA-1273 SARS-CoV-2 vaccine. $N$ Engl $J$ Med. 2021;384 (5):403-416. doi:10.1056/NEJMoa2035389

5. Greinacher A, Thiele T, Warkentin TE, Weisser K, Kyrle PA, Eichinger S. Thrombotic thrombocytopenia after ChAdOx1 nCov-19 vaccination. $N$ Engl J Med. 2021;384(22):2092-2101. doi:10.1056/ NEJMoa2104840
6. Schultz NH, Sørvoll IH, Michelsen AE, et al. Thrombosis and thrombocytopenia after ChAdOx1 $\mathrm{nCoV}-19$ vaccination. $N$ Engl $J$ Med. 2021;384(22):2124-2130. doi:10.1056/NEJMoa2104882

7. Muir KL, Kallam A, Koepsell SA, Gundabolu K. Thrombotic thrombocytopenia after Ad26.COV2.S vaccination. $N$ Engl $J$ Med. 2021;384(20):1964-1965. doi:10.1056/NEJMc2105869

8. Brown DM, Heier JS, Clark WL, et al. Intravitreal aflibercept injection for macular edema secondary to central retinal vein occlusion: 1-year results from the Phase 3 COPERNICUS study. Am J Ophthalmol. 2013;155(3):429-437.e7. doi:10.1016/j.ajo.2012.09.026

9. Boyer D, Heier J, Brown DM, et al. Vascular endothelial growth factor Trap-Eye for macular edema secondary to central retinal vein occlusion: six-month results of the phase 3 COPERNICUS study. Ophthalmology. 2012;119(5):1024-1032. doi:10.1016/j. ophtha.2012.01.042

10. Korobelnik JF, Holz FG, Roider J, et al. Intravitreal aflibercept injection for macular edema resulting from central retinal vein occlusion: one-year results of the phase 3 GALILEO study. Ophthalmology. 2014;121(1):202-208. doi:10.1016/j.ophtha.2013. 08.012

11. Holz FG, Roider J, Ogura Y, et al. VEGF Trap-Eye for macular oedema secondary to central retinal vein occlusion: 6-month results of the Phase III GALILEO study. Br J Ophthalmol. 2013;97 (3):278-284. doi:10.1136/bjophthalmol-2012-301504

12. Asahi MG, Bobarnac Dogaru GL, Onishi SM, Gallemore RP. Strong topical steroid, NSAID, and carbonic anhydrase inhibitor cocktail for treatment of cystoid macular edema. Int Med Case Rep J. 2015;8:305-312. doi:10.2147/IMCRJ.S92794

13. Mareev VY, Orlova YA, Pavlikova EP, et al. Steroid pulse -therapy in patients With coronAvirus Pneumonia (COVID-19), sYstemic inFlammation And Risk of vEnous thRombosis and thromboembolism (WAYFARER Study). Kardiologiia. 2020;60(6):15-29. English, Russian. doi:10.18087/cardio.2020.6.n1226

14. Nutescu EA, Burnett A, Fanikos J, Spinler S, Wittkowsky A. Pharmacology of anticoagulants used in the treatment of venous thromboembolism [published correction appears in $\mathrm{J}$ Thromb Thrombolysis. 2016 Aug;42(2):296-311]. J Thromb Thrombolysis. 2016;41(1):15-31. doi:10.1007/s11239-015-1314-3

15. Oldenburg J, Klamroth R, Langer F, et al. Diagnosis and management of vaccine-related thrombosis following AstraZeneca COVID-19 vaccination: guidance statement from the GTH. Hamostaseologie. 2021. doi:10.1055/a-1469-7481

16. Khan P, Khan L, Awasthi U, Khan A, Siddique Z, Chand R. Pentoxifylline: a therapeutic remedy for optic neuropathies. $J$ Evol Med Dent Sci. 2013;2:3516-3522. doi:10.14260/jemds/722

17. Hurst KV, O'Callaghan JM, Handa A. Quick reference guide to apixaban [published correction appears in Vasc Health Risk Manag. 2017 Oct 26;13:413]. Vasc Health Risk Manag. 2017;13:263-267. doi:10.2147/VHRM.S121944

18. Hayreh SS. Management of ischemic optic neuropathies. Indian J Ophthalmol. 2011;59(2):123-136. doi:10.4103/0301-4738.77024

19. Miller NR. Current concepts in the diagnosis, pathogenesis, and management of nonarteritic anterior ischemic optic neuropathy. $J$ Neuroophthalmol. 2011;31(2):e1-3. doi:10.1097/WNO.0b013e3 $1821 \mathrm{f} 955 \mathrm{c}$

20. Atkins EJ, Bruce BB, Newman NJ, Biousse V. Treatment of nonarteritic anterior ischemic optic neuropathy. Surv Ophthalmol. 2010;55(1):47-63. doi:10.1016/j.survophthal.2009.06.008

21. Quiros P, Hirsch L, Sadun A. The use of pentoxifylline in the prevention of second eye involvement in patients with NAION. North Am Neuro Ophthalmol Soc. 2011;poster 120. https://collec tions.lib.utah.edu/details?id $=181718 \&$ page $=17 \&$ facet_setname_s $=$ ehsl_novel_nam 


\section{Publish your work in this journal}

The International Medical Case Reports Journal is an international, peer-reviewed open-access journal publishing original case reports from all medical specialties. Previously unpublished medical posters are also accepted relating to any area of clinical or preclinical science. Submissions should not normally exceed 2,000 words or 4 published pages including figures, diagrams and references. The manuscript management system is completely online and includes a very quick and fair peer-review system, which is all easy to use. Visit http://www.dovepress.com/testimonials.php to read real quotes from published authors. 